\title{
An Update on the Amyloid Hypothesis
}

\author{
Christopher B. Eckman, $\mathrm{PhD}^{\mathrm{a}, *}$, \\ Elizabeth A. Eckman, $\mathrm{PhD}^{\mathrm{b}}$ \\ a Department of Neuroscience, Mayo Clinic College of Medicine, Birdsall Building Room 306, \\ 4500 San Pablo Road, Jacksonville, FL 32224, USA \\ ${ }^{\mathrm{b}}$ Department of Neuroscience, Mayo Clinic College of Medicine, Birdsall Building Room $318 a$, \\ 4500 San Pablo Road, Jacksonville, FL 32224, USA
}

Alzheimer's disease (AD) is a devastating disease, not only for patients but also for their families and loved ones. What typically begins as fairly subtle memory loss progresses relentlessly over a period of approximately 7-10 years, until all higher cognitive functions are eroded and AD patients are robbed of their identity and ability to interact with the outside world. Currently, estimates indicate that more than 27 million individuals are affected by AD worldwide [1]. In the United States alone, more than 4 million individuals have the disease [2]. Unfortunately, without a cure or a means to otherwise prevent this disease or significantly slow its progression, the number of affected individuals in the United States is expected to triple by 2050 due to the aging baby boomer generation [2]. This enormous increase in the number of affected individuals is likely to have dire consequences on the already overburdened health care system in this country.

Based on the statistics alone, the identification of novel therapeutic or preventative agents is of considerable importance. To rationally develop these agents, an understanding of the etiology and pathogenesis of this complex disease is necessary. Over the past century, numerous hypotheses have been proposed, including abnormal phosphorylation of tau, unconventional infectious agents, trace element neurotoxicity, growth factor deficiency, excitatory amino acid insult, altered calcium homeostasis, free radical toxicity, deficits in energy metabolism, and altered protein processing resulting in abnormal $\beta$-amyloid peptide (A $\beta$ ) accumulation (reviewed in part by

This work was supported by grants from the National Institutes of Neurological Diseases and Stroke (NIH 5R01NS042192 and NIH 5R01NS048554) and by the Mayo Foundation for Medical Education and Research.

* Corresponding author.

E-mail address: eckman@mayo.edu (C.B. Eckman). 
Markesbery [3]). Most importantly, any hypothesis describing the etiology and pathogenesis of AD must take into account the neurologic and neuropathologic features of AD as well as the known genetic risk factors, causative mutations, and the heightened risk associated with advanced age.

One such comprehensive hypothesis, that has received significant attention over the past 2 decades (for better or for worse), is the amyloid hypothesis [4-6]. Although many iterations of this hypothesis currently exist, the initial hypothesis stated that the "deposition of amyloid $\beta$ protein (A $\beta P$ ), the main component of the plaques, is the causative agent of Alzheimer's pathology..." [5]. This article examines the evidence for this hypothesis and its potential limitations, particularly related to the development of novel therapeutic and preventative agents.

\section{Neuropathology of Alzheimer's disease and the identification of beta-amyloid}

The first evidence for the amyloid hypothesis came from neuropathologic assessments of brains isolated from AD patients. The earliest examinations published by Alois Alzheimer described the neuropathology in two patients [7-9], and revealed a diffuse atrophy primarily of the cerebral cortex. Staining of the brains isolated from these two patients demonstrated the presence of two types of lesions. The first type, now known as neurofibrillary tangles (NFTs), was observed in the initial patient, and was described as a twisted coil of fibrils derived from degenerating cerebral cortical cells. The second type of lesion, now known as senile plaques, was present in both of the cases to differing degrees. These plaques were found throughout the cerebral cortex and were characterized by a central core surrounded by a more diffuse halo.

We now know that these classical senile plaques are complex, extracellular lesions that are associated with degenerating neuronal processes, have activated microglia intertwined with the central deposit, and are surrounded by reactive astrocytes. These deposits are found throughout the neocortex and hippocampus in patients who have AD [10]. The central deposit in classical senile plaques structurally is similar to the deposits seen in a group of diseases referred to as amyloidoses, wherein there is extracellular deposition of proteins with a beta-pleated sheet conformation (reviewed by Sipe $[11,12])$. More than 15 different polypeptides have been identified as the primary proteinaceous components of the amyloids that are deposited in various tissues in the clinically diverse amyloidoses.

The central location of the plaque core within this pathology led to the speculation that whatever comprises the core may play a pivotal role in the disease process itself. In a landmark finding in 1984, Glenner and Wong published the purification and sequence of the primary proteinaceous component of amyloid isolated from meningeal vessels obtained from AD brains [13]. By comparing samples from six AD patients and three controls, 
they identified a unique protein only present in the patients who had AD. Size-exclusion chromatography revealed that the protein had an approximate molecular weight of 4200 daltons, and amino acid analysis and sequencing revealed a novel amino acid sequence now referred to as $\mathrm{A} \beta$.

\section{Alzheimer's disease and Down syndrome: the link to chromosome 21}

Previously, it was established that individuals who have Down syndrome who live past age 50 have neuropathologic changes similar to AD patients (reviewed by Mann [14]). In a follow-up to their original finding, Glenner and Wong [15] isolated and analyzed the cerebrovascular amyloid from Down syndrome patients. They established that the amino acid sequence of cerebrovascular amyloid in Down syndrome is identical to that observed in AD patients. Given the similarity of the amyloid deposited in AD and Down syndrome, Glenner and Wong [15] proposed that there was a common pathogenic process involved. Down syndrome results from trisomy of the twenty-first chromosome, which implied that AD pathology could be produced by increased expression of a gene or genes on chromosome 21 .

After these initial reports, amino acid sequencing of the amyloid isolated from senile plaques from $\mathrm{AD}$ and Down syndrome brains was reported by other groups $[16,17]$. These reports established that the amino-terminal sequence and amino acid composition of plaque core amyloid was identical to that of cerebrovascular amyloid isolated from $\mathrm{AD}$ or Down syndrome brains, except for the presence of ragged $\mathrm{NH}_{2}$ termini [17].

To isolate the gene encoding $A \beta$, Kang and colleagues [18] used degenerate primers targeted against amino acids 10-16 of the peptide to screen a complementary DNA library constructed from the brain of a 5-month old fetus. In these experiments, they isolated a clone encoding a 695 amino acid protein that contained the $A \beta$ sequence beginning 99 amino acids from the carboxyl end of the protein. This protein was simultaneously reported by other groups and is now known as $\beta$-amyloid protein precursor ( $\beta$ APP) [19-21]. Southern blot analysis of mouse/human cell hybrids revealed that the gene encoding $\beta A P P$ is located on the twenty-first chromosome [18]. This data substantiated Glenner and Wong's previous suggestion, that overexpression of a gene or genes on chromosome 21 should be sufficient to cause AD pathology. Subsequent studies by Tamaoka and colleagues showed that $A \beta$ levels were increased significantly in plasma isolated from patients who had Down syndrome when compared with control individuals, indicating that an increased copy number of $\beta A P P$ does result in increased levels of $A \beta$ in humans [22].

\section{$\beta$-amyloid protein precursor metabolism}

A basic description of the metabolism of $\beta A P P$ is necessary to understand how the familial AD (FAD)-linked mutations (discussed later) can 
influence the accumulation of $A \beta$. The $A \beta$ peptide sequence is embedded in the $\beta$ APP protein, indicating that two separate proteolytic cleavages are required to generate $A \beta$ from its precursor. The $\mathrm{N}$-terminus of $A \beta$ is generated by cleavage of $\beta$ APP by $\beta$-secretase, producing a 99 amino acid $C$-terminal fragment (CTF) of $\beta$ APP that can be cleaved further by $\gamma$-secretase to release $A \beta$. $\gamma$-Secretase generates two major $A \beta$ species, 40 and 42 amino acids in length, termed $A \beta 40$ and $A \beta 42$. $\beta A P P$ also can be cleaved within the $A \beta$ domain by $\alpha$-secretase, an action that precludes $A \beta$ generation. The $\beta$ - and $\gamma$-secretase cleavages are discussed further with descriptions of the discovery of the three genes linked to familial early-onset AD and the mechanisms by which they elevate $A \beta$ levels.

\section{Genetics of Alzheimer's disease}

Some of the strongest evidence for a critical role for $\mathrm{A} \beta$ in $\mathrm{AD}$ came from an analysis of the genetic mutations that cause AD. In addition to trisomy 21 causing neuropathology that essentially is identical to that seen in typical late-onset $\mathrm{AD}, \mathrm{AD}$ can be inherited as a fully penetrant, autosomal dominant trait in certain families [23-24]. In these families, the clinical and neuropathologic presentation of the disease essentially is identical to typical late-onset AD, but the age of onset is earlier, typically in the 50s. Mutations in three distinct genes, on three separate chromosomes, have been identified as the cause of $\mathrm{AD}$ in these families: the $\beta \mathrm{APP}$ gene on chromosome 21 [25-29], the presenilin 1 gene on chromosome 14 [30], and the presenilin 2 gene on chromosome 1 [31]. These genes are reviewed in greater detail in the article by Taner and colleagues elsewhere in this issue. However, some of FAD-linked mutations are highlighted below as they relate to the amyloid hypothesis.

The first mutation shown to cause $\mathrm{AD}$, found in a single family, was a point mutation in the $\beta A P P$ gene itself. This mutation results in a substitution of the more hydrophobic amino acid, isoleucine, for valine at position 717 (V717I), which is immediately carboxyl to the $A \beta$ sequence [26]. In other families, additional mutations at this position subsequently were identified that result in the substitution of phenylalanine (V717F) [25] or glycine (V717G) [27]. After the identification of mutations at position 717 in the $\beta A P P$ gene, a double mutation at position $670 / 671$ was identified in a large Swedish family with a mean age of onset of AD of 55 years [28]. The 670/671 double mutation results in a substitution of asparagine and leucine for the lysine and methionine, respectively, immediately preceding the $\mathrm{N}$-terminus of $A \beta(\mathrm{K} 670 \mathrm{~N} / \mathrm{M} 671 \mathrm{~L})$. In context, the identification of causative mutations for $\mathrm{AD}$, not only within the $\beta$ APP protein itself but also immediately adjacent to the cleavage sites needed to liberate the $A \beta$ peptide from its precursor protein, provided additional, immediate support for the amyloid hypothesis. 
To investigate the hypothesis that the mutations identified in the $\beta A P P$ gene would alter the amount of $A \beta$ peptide being produced, several groups turned their attention to the analysis of $\beta$ APP metabolism and extracellular $\mathrm{A} \beta$ accumulation in model systems [32-35]. Analysis of total $A \beta$ concentration in the conditioned medium of transfected cells expressing these FAD-linked mutations indicated that the Swedish mutation caused a several-fold increase in the amount of $A \beta$ accumulated extracellularly $[32,33]$. Additionally, analysis of the CTFs and secreted forms of $\beta A P P$ (sAPP) showed elevations in CTF $\beta$ and $\mathrm{SAPP} \beta$, indicating that the increased $A \beta$ concentration observed with this mutation is likely the result of enhanced $\beta$ secretase cleavage [36]. Using the same experimental paradigm, no significant differences in total A $\beta$, CTFs, or sAPPs were observed, however, in cells transfected with the 717 mutations [35].

Pioneering work by Lansbury and colleagues [37-39] showed that the carboxy-terminal length of the $A \beta$ molecule was critical to determining the rate at which $A \beta$ fibrils form. Using synthetic peptides, they showed that $A \beta$ ending at position 42 formed fibrils far more rapidly and at lower concentrations than $A \beta$ ending at position 40. As the deposition of $A \beta$ in the form of amyloid fibrils represents an invariant feature of $\mathrm{AD}$, Younkin and colleagues [33] proposed that the 717 mutations might be acting to selectively increase secretion of $A \beta 42$. In a landmark finding, Younkin's group showed that secreted $A \beta 42$, which normally constitutes only a fraction of total secreted $A \beta$, is increased significantly in the medium of cells expressing the 717 mutations [35]. Thus, both the Swedish mutation and the 717 mutations increase the concentration of $A \beta$, in particular $A \beta 42$.

To date, one of the greatest tests of the amyloid hypothesis involved the analysis of mutations that also cause early-onset AD but that do not reside in the $\beta A P P$ gene or even on chromosome 21. These were the presenilin mutations. (These are covered in detail the article by Taner and colleagues elsewhere in this issue.) Initially, there was no evidence to suggest that these genes were involved with $\beta A P P$ processing. In fact, they seemed equally as likely to directly influence tau, synapse loss, energy metabolism, or a host of other factors associated with alternate theories regarding the etiology and pathogenesis of $\mathrm{AD}$.

However, studies performed by Younkin and colleagues [40] showed that in cultured medium from primary fibroblasts and plasma isolated from patients who had either presenilin 1 or presenilin 2 mutations, $A \beta$ levels were elevated, in particular $A \beta 42$ levels, similar to the 717 mutations in $\beta A P P$. Follow-up studies by several groups examining the influence of these mutations on $A \beta$ levels in either transfected cells or in the brains of animals transgenic for these mutations confirmed these findings.

When the presenilins were discovered as FAD-linked genes in 1995, their functions were unknown and their link to APP metabolism was not clear. Then, in 1997, Selkoe and colleagues [41] showed that APP and presenilin interact in mammalian cells, as evidenced by coimmunoprecipitation 
experiments. Over the next 5 years, several additional laboratories demonstrated that the presenilins are the catalytic component of the multiprotein complex that is $\gamma$-secretase [42-44]. Consequently, the relationship between $\beta A P P$, the presenilins, and AD now is clear: $A \beta$ is generated by $\beta$-secretase and $\gamma$-secretase (presenilin complex) cleavage of the $\beta$ APP protein. All of the mutations identified in $\beta A P P$, presenilin 1 , and presenilin 2 that cause early-onset FAD increase $A \beta$ levels, particularly $A \beta 42$ levels, or otherwise perturb the ratio of $A \beta 42$ to $A \beta 40$ levels [45] in ways likely to foster $A \beta$ aggregation and deposition.

\section{$\beta$-amyloid peptide levels increase during aging}

Aging clearly is the most significant risk factor associated with $\mathrm{AD}$, and $A \beta$ levels begin to increase in the brains of many people who are cognitively normal between the ages of 40 and 80 [46,47]. According to the study of consecutive autopsy cases by Funato and colleagues [46], insoluble A $\beta 42$ in particular accumulates with age in the cortex and precedes senile plaque formation. Compared with brains from cognitively normal elderly individuals, AD brain had higher levels of soluble and insoluble $A \beta 42$ and $A \beta 40$ and a higher degree of $N$-terminally truncated or modified $A \beta$. Similar correlations between $A \beta$ levels and age in individuals who were cognitively normal were reported by Morishima-Kawashima and colleagues [47], with significant increases in $A \beta$ accumulation beginning after age 40. In both studies, insoluble $A \beta$ concentration was related logarithmically to plaque density, and a critical threshold (approximately $100 \mathrm{pmol} / \mathrm{g}$ ) of insoluble A $\beta 42$ was required for immunocytochemical detection of senile plaques. In the latter study, carriers of the apolipoprotein $E \in 4$ allele, a strong risk factor for $\mathrm{AD}$, were found to accumulate $\mathrm{A} \beta$ at an earlier age than noncarriers [47].

\section{Increased levels of $\beta$-amyloid peptide: causative agent or very good biomarker?}

As discussed previously, elevations in $A \beta$ concentration that are likely to enhance aggregation and deposition are linked to the expression of all of the FAD-linked mutations analyzed to date, and in Down syndrome. These elevations can be detected in plasma and in fibroblast-conditioned medium isolated from presymptomatic individuals $[36,48]$ and in transgenic animals before deposition [49,50], suggesting that these changes are early and not simply an epiphenomenon associated with end-stage AD. In addition it seems that $A \beta$ levels increase during aging in humans and in animal models, with age being the highest contributing risk factor for the development of the disease. 
The question then remains, do elevations in A $\beta$ play a central, causal role in the pathogenesis of the disease or are they a relatively benign marker of the underlying disease process. Perhaps this question will not be answered until newly developed approaches to lower $\mathrm{Ab}$ either fail or show significant improvement in the clinics. However, it can be concluded, based on numerous studies, that elevations in $\mathrm{Ab}$ levels are not likely without consequence.

\section{Clinical-neuropathologic correlations in Alzheimer's disease}

The extent of correlation between the neuropathologic lesions in AD patients and the severity of their dementia has been an area of considerable debate and continues to be used consistently as an argument against the amyloid hypothesis. As is true with any correlative function, a correlation can be a good indicator of a causal relationship, but close correlation is not definitive proof of causality. For example, a well-correlated change simply can be an inconsequential, reliable biomarker of another process that is causative. With that in mind, some of the earliest studies showed significant correlations between plaque numbers and the extent of dementia [51]. Several other studies, however, reported that the number of NFTs and neuropil threads is a far better indicator of the degree of dementia [52,53]. One of the most comprehensive recent analyses, with respect to the extent of variables examined, was published by Cummings and colleagues [54]. In this study, they found that the number of plaques, NFTs, and dystrophic neurites all correlated significantly with dementia severity and the area occupied by $\mathrm{A} \beta$ and tau paired-helical filaments. However, individuals remain who have extensive amyloid deposition and are cognitively normal. For example, in a study by Markesbery's group, significant AD-like pathology (plaques and tangles) was found in the brains of a substantial number of elderly, cognitively normal individuals [55]. These and similar studies led some to argue that the amyloid hypothesis must be wrong. In response, some amyloid theory proponents have adjusted the hypothesis accordingly to accommodate and now argue for preamyloid-like aggregates of $A \beta$, such as $A \beta$ oligomers, as the causative agent in the disease process. Regardless of the correct hypothesis, the development of AD is a reasonably long process. Therefore, it is not surprising that with nearly one half of the population susceptible to the disease, if they live long enough, individuals can be found who have significant neuropathology and who are cognitively normal. Similar trends are observed in other neurodegenerative diseases, such as Parkinson's disease, where approximately $70 \%$ of the dopaminergic neurons in the subtantia nigra are lost before the development of clinical symptoms.

\section{$\beta$-amyloid peptide toxicity}

If alterations in $A \beta$ are necessary and sufficient to play a causal role in $A D$ pathogenesis, then $A \beta$ should be able to elicit, directly or indirectly, the 
neuropathologic and cognitive changes observed in patients who have AD. Furthermore, mechanisms must exist that can explain the prevalence of the disease in the aging population and in people carrying causative mutations and known genetic risk factors. Evidence gathered over the past several years builds an increasingly stronger case that the alterations in $A \beta$ observed in the genetic forms of $\mathrm{AD}$ are not without consequence and can account for the neuropathology and dementia in AD. This section reviews evidence for the neurotoxicity of abnormal $A \beta$ species. Although neurotoxicity initially was attributed to the fibrillar species of $A \beta$ deposited in plaques, recent data also implicate soluble $A \beta$ oligomers, which may form before plaque deposition and cause neuronal dysfunction that may facilitate many of the downstream pathologic events in AD. Because these soluble oligomers exist in equilibrium with fibrillar $A \beta$ as deposition progresses, the neuronal loss, inflammation, and other pathology seen in the vicinity of plaques may be the result of the oligomers, the plaques, or a combination of the two.

Soluble, synthetic $A \beta$ peptides were shown by Yankner and colleagues [56] to be neurotrophic at low concentration to undifferentiated hippocampal neurons in culture and toxic at higher concentrations to mature neurons. Subsequently, the neurotoxicity of $\mathrm{A} \beta$ was shown to be dependent on its aggregation state $[57,58]$. Stable $A \beta$ aggregates were highly toxic to primary neurons, and partial reversal of aggregation resulted in a loss of toxicity. Similar results were found in in vivo studies, with microinjection of fibrillar, but not soluble, $A \beta$ causing neurotoxicity in the cerebral cortex of aged rhesus monkeys [59]. Neurotoxicity was dependent not only on the aggregation state of $A \beta$ but also on the age and species of the animal model used. Specifically, plaque-equivalent concentrations of fibrillar $\mathrm{A} \beta$ resulted in extensive neuronal loss, tau phosphorylation, and microglial activation in the brains of aged monkeys but were not toxic to young adult monkeys or aged rodents. Much higher concentrations of $\mathrm{A} \beta$ were required to elicit neurotoxicity in young adult monkeys and in rodents [59-61]. These results may help to explain the vulnerability of the elderly to AD and the difficulty of generating a rodent model that faithfully reproduces all of the neuropathologic features of the disease.

In vitro, fibrils are believed to form via the progression from $\mathrm{A} \beta$ monomers to low-molecular-weight oligomers to intermediate species (called protofibrils) that assemble into mature fibrils [62]. The data indicating that $\mathrm{A} \beta$ fibrils are neurotoxic and can elicit other AD characteristics, including tau phosphorylation, suggested that disrupting fibrils might be therapeutically beneficial. However, researchers suspected that the disruption of insoluble A $\beta$ fibrils could result in an accumulation of protofibrils and other soluble oligomers. Therefore, experiments were performed to investigate whether these lower-level aggregates apparently were nontoxic, like A $\beta$ monomers, or whether they might elicit neurotoxic effects, like fibrils. Data generated over the past several years demonstrates convincingly that $A \beta$ oligomers neurotoxic, and in many assays they are even more toxic than fibrils [63]. 
Soluble oligomers range from dimers and trimers to dodecamers, also called A $\beta$-derived diffusible ligands (ADDLs) $[64,65]$. The smaller sodium dodecyl sulfate (SDS) stable oligomers are produced by several cell lines and have been detected in human brain and cerebrospinal fluid. Similarly, the larger ADDLs are not merely an artifact of the in vitro assembly of $A \beta$, as structurally indistinguishable $A \beta$ oligomers are present in soluble extracts of AD brain at average levels 12-fold higher than in control brains [66]. ADDLs, formed in vitro or purified from AD brain, bind specifically to synapses in differentiated hippocampal neuronal cultures [63]. This evidence for specific neuronal attachment, coupled with the fact that ADDLs and lower-molecular-weight $A \beta$ oligomers are shown to be potent inhibitors of long-term potentiation, a model of synaptic plasticity and memory, provides a rational explanation for early memory loss in AD and in animal models of AD $[64,67,68]$.

As discussed previously, a common criticism of the amyloid hypothesis was that in some studies, plaque burden correlated poorly with severity of dementia in $\mathrm{AD}$. The discovery of soluble oligomers as neurotoxic $\mathrm{A} \beta$ species led to an examination of the relationship between soluble $A \beta$ concentration and clinical and pathologic severity. A strong correlation between soluble $A \beta$ and markers of disease severity, including synaptic loss, was identified $[69,70]$. Two additional lines of evidence support the hypothesis that soluble $A \beta$ oligomers are the primary toxic entity in the brain, at least in animal models.

First, impaired synaptic transmission and cognitive function are seen before overt amyloid deposition in mouse models of $\mathrm{AD}$ [71-73]. In the widely used APP transgenic mouse model, Tg2576, a partial decline in memory occurs at approximately 6 months, before amyloid deposition. Cognitive function then remains stable over the next 7 to 8 months, even though plaque deposition progresses and becomes significant over this time period. Finally, a further decline in cognitive function is detected at ages greater than 15 months. The initial memory decline at 6 months, followed by the period of stability, was perplexing in terms of the lack of correlation with the course of amyloid plaque deposition in this model. This led Lesné and colleagues [72] to conduct a detailed biochemical analysis of $\mathrm{A} \beta$ complexes in the brains of these mice during the time period when the first behavioral deficits are detected. Soluble, extracellular-enriched extracts from the forebrain of 6-month-old Tg2576 contained SDS and urea stable A $\beta$ complexes with molecular weights theoretically corresponding to trimers and multiples thereof, up to a molecular weight of $56 \mathrm{kd}$. Only the 56-kd (theoretic dodecamer) and 40-kd (theoretic nonamer) species appeared for the first time at 6 months. Both correlated inversely with memory performance, with the 56-kd form (termed $A \beta * 56$ ) showing the strongest correlation. The levels of the 40- and 56-kd A $\beta$ complexes remained stable on average during the subsequent period of cognitive stability in the mice. To test more directly whether or not $A \beta * 56$ causes cognitive impairment, the 
complexes were purified from Tg2576 brain extracts and then injected into the lateral ventricle of rats. $A \beta^{*} 56$ caused a transient decrease in spatial memory in rats, supporting the hypothesis that this complex could be responsible for the onset of memory deficits in the $\mathrm{Tg} 2576$ mouse model [72]. Whether or not $A \beta^{* 56}$ structurally is identical to the 56-kd ADDLs derived from $\mathrm{AD}$ brain [66] is an intriguing question that remains to be determined.

Second, therapeutic interventions, which lower the level of soluble $A \beta$ or disrupt $A \beta$ assembly in animal models, often in the absence of detectable changes in plaque load, ameliorate cognitive deficits [74-79]. This effect is not unique to a single therapeutic approach and has been observed with such divergent strategies as A $\beta$ immunization, acute $\gamma$-secretase inhibition, and oligomer neutralization. Recently, Lee and colleagues [77] showed that short-term passive immunization of aged Tg2576 APP transgenic mice with a conformation-specific $A \beta$ antibody that preferentially recognizes dimers, soluble oligomers, and certain amyloid deposits resulted in significant improvements in spatial learning and memory without affecting amyloid burden. These results are similar to those obtained by independent groups using different $A \beta$ antibodies and different transgenic lines [75,76] and support the hypothesis that the neutralization of toxic $A \beta$ species can reverse cognitive deficits in mice. This hypothesis has recently been tested by other investigators [78] using a completely different experimental paradigm but with similar results [78,79]. Cyclohexanehexol stereoisomers, which inhibit $A \beta$ aggregation and favor the disassembly of fibrils, can prevent $A \beta$ oligomer-induced toxicity in cultured primary neurons and hippocampal slices and oligomer-induced memory deficits in rats [79]. When administered orally to TgCRND8 APP transgenic mice from 6 weeks of age (predeposition) to 4 to 6 months (significant amyloid deposition), scyllo-cyclohanehexol showed a dose-dependent improvement in spatial learning accompanied by decreases in amyloid burden and $A \beta$ oligomers [78]. Synaptic loss was ameliorated at 6 months as was accelerated mortality in the treated mice.

Perhaps the most important implication of these studies is that the cognitive impairment in these models is not permanent. To what degree this applies to the human condition is unknown, because the profound neuronal loss in $\mathrm{AD}$ is absent in AD mouse models. Nonetheless, reducing soluble A $\beta$ levels or altering a toxic conformation may be a less ambitious goal than clearing plaques. The true test for the amyloid hypothesis of AD, and the specific notion that soluble oligomers mediate $A \beta$ toxicity, awaits the further development of $A \beta$-targeted therapies and their progression to clinical trial.

\section{References}

[1] Wimo A, Jonsson L, Winblad B. An estimate of the worldwide prevalence and direct costs of dementia in 2003. Dement Geriatr Cogn Disord 2006;21(3):175-81. 
[2] Hebert LE, Scherr PA, Bienias JL, Bennett DA, Evans DA. Alzheimer disease in the US population: prevalence estimates using the 2000 census. Arch Neurol Aug 2003;60(8):1119-22.

[3] Markesbery WR. Alzheimer's Disease. In: Asbury AK, McKhann GM, McDonald WI, editors. Diseases of the Nervous System: Clinical Neurobiology, Vol I. 2 edition. Philadelphia: W.B. Saunders Company; 1992.

[4] Hardy J, Allsop D. Amyloid deposition as the central event in the aetiology of Alzheimer's disease. Trends Pharmacol Sci Oct 1991;12(10):383-8.

[5] Hardy JA, Higgins GA. Alzheimer's disease: the amyloid cascade hypothesis. Science Apr 10 1992;256(5054):184-5.

[6] Selkoe DJ. The molecular pathology of Alzheimer's disease. Neuron Apr 1991;6(4): 487-98.

[7] Alzheimer A. Uber eine eigenartige, Erkrankung der Hirnrinde. Allg Z Psychiatrie Psychisch-Gerichtl Med 1907;64:146-8.

[8] Alzheimer A. Uber eigenartige Krankheitsfalle des spateren Alters. Zbl Ges Neurol Psych 1911;4:356-85.

[9] Moller HJ, Graeber MB. The case described by Alois Alzheimer in 1911. Historical and conceptual perspectives based on the clinical record and neurohistological sections. Eur Arch Psychiatry Clin Neurosci 1998;248(3):111-22.

[10] Selkoe DJ. Cellular and molecular biology of the beta-amyloid precursor protein and Alzheimer's disease. In: Rosenberg RN, Pruisner SB, DiMauro S, Barchi RL, editors. The Molecular and Genetic Basis of Neurological Disease. 2 edition. Boston: Butterworth-Heinemann; 1997. p. 601-11.

[11] Sipe JD. Amyloidosis. Annu Rev Biochem 1992;61:947-75.

[12] Sipe JD. Amyloidosis. Crit Rev Clin Lab Sci 1994;31(4):325-54.

[13] Glenner GG, Wong CW. Alzheimer's disease: initial report of the purification and characterization of a novel cerebrovascular amyloid protein. Biochem Biophys Res Commun 1984;120(3):885-90.

[14] Mann DM. Alzheimer's disease and Down's syndrome. Histopathology 1988;13(2):125-37.

[15] Glenner GG, Wong CW. Alzheimer's disease and Down's syndrome: sharing of a unique cerebrovascular amyloid fibril protein. Biochem Biophys Res Commun 1984;122(3):1131-5.

[16] Gorevic PD, Goni F, Pons-Estel B, Alvarez F, Peress NS, Frangione B. Isolation and partial characterization of neurofibrillary tangles and amyloid plaque core in Alzheimer's disease: immunohistological studies. J Neuropathol Exp Neurol 1986;45(6):647-64.

[17] Masters CL, Simms G, Weinman NA, Multhaup G, McDonald BL, Beyreuther K. Amyloid plaque core protein in Alzheimer disease and Down syndrome. Proc Natl Acad Sci U S A 1985;82(12):4245-9.

[18] Kang J, Lemaire HG, Unterbeck A, et al. The precursor of Alzheimer's disease amyloid A4 protein resembles a cell-surface receptor. Nature 1987;325(6106):733-6.

[19] Robakis NK, Ramakrishna N, Wolfe G, Wisniewski HM. Molecular cloning and characterization of a cDNA encoding the cerebrovascular and the neuritic plaque amyloid peptides [published erratum appears in Proc Natl Acad Sci U S A 1987 Oct;84(20):7221]. Proc Natl Acad Sci U S A 1987;84(12):4190-4.

[20] Tanzi RE, Gusella JF, Watkins PC, et al. Amyloid beta protein gene: cDNA, mRNA distribution, and genetic linkage near the Alzheimer locus. Science 1987;235(4791):880-4.

[21] Goldgaber D, Lerman MI, McBride OW, Saffiotti U, Gajdusek DC. Characterization and chromosomal localization of a cDNA encoding brain amyloid of Alzheimer's disease. Science 1987;235(4791):877-80.

[22] Tokuda T, Fukushima T, Ikeda S, et al. Plasma levels of amyloid beta proteins Abeta1-40 and Abeta1-42(43) are elevated in Down's syndrome. Ann Neurol 1997;41(2):271-3.

[23] Hardy J. Amyloid, the presenilins and Alzheimer's disease [see comments]. Trends Neurosci 1997;20(4):154-9.

[24] Blacker D, Tanzi RE. The genetics of Alzheimer disease: current status and future prospects. Arch Neurol 1998;55(3):294-6. 
[25] Murrell J, Farlow M, Ghetti B, Benson MD. A mutation in the amyloid precursor protein associated with hereditary Alzheimer's disease. Science 1991;254(5028):97-9.

[26] Goate A, Chartier-Harlin MC, Mullan M, et al. Segregation of a missense mutation in the amyloid precursor protein gene with familial Alzheimer's disease [see comments]. Nature 1991;349(6311):704-6.

[27] Chartier-Harlin MC, Crawford F, Houlden H, et al. Early-onset Alzheimer's disease caused by mutations at codon 717 of the beta-amyloid precursor protein gene. Nature 1991; 353(6347):844-6.

[28] Mullan M, Crawford F, Axelman K, et al. A pathogenic mutation for probable Alzheimer's disease in the APP gene at the N-terminus of beta-amyloid. Nat Genet 1992;1(5):345-7.

[29] Eckman CB, Mehta ND, Crook R, et al. A new pathogenic mutation in the APP gene (I716V) increases the relative proportion of A beta 42(43). Hum Mol Genet 1997;6(12): 2087-9.

[30] Sherrington R, Rogaev EI, Liang Y, et al. Cloning of a gene bearing missense mutations in early-onset familial Alzheimer's disease [see comments]. Nature 1995;375(6534):754-60.

[31] Levy-Lahad E, Wasco W, Poorkaj P, et al. Candidate gene for the chromosome 1 familial Alzheimer's disease locus [see comments]. Science 1995;269(5226):973-7.

[32] Citron M, Oltersdorf T, Haass C, et al. Mutation of the beta-amyloid precursor protein in familial Alzheimer's disease increases beta-protein production. Nature 1992;360(6405): $672-4$.

[33] Cai XD, Golde TE, Younkin SG. Release of excess amyloid beta protein from a mutant amyloid beta protein precursor [see comments]. Science 1993;259(5094):514-6.

[34] Citron M, Vigo-Pelfrey C, Teplow DB, et al. Excessive production of amyloid betaprotein by peripheral cells of symptomatic and presymptomatic patients carrying the Swedish familial Alzheimer disease mutation. Proc Natl Acad Sci U S A 1994;91(25): 11993-7.

[35] Suzuki N, Cheung TT, Cai XD, et al. An increased percentage of long amyloid beta protein secreted by familial amyloid beta protein precursor (beta APP717) mutants. Science 1994; 264(5163): $1336-40$.

[36] Felsenstein KM, Hunihan LW, Roberts SB. Altered cleavage and secretion of a recombinant beta-APP bearing the Swedish familial Alzheimer's disease mutation. Nat Genet 1994;6(3): 251-5.

[37] Jarrett JT, Berger EP, Lansbury PT Jr. The C-terminus of the beta protein is critical in amyloidogenesis. Ann N Y Acad Sci 1993;695:144-8.

[38] Jarrett JT, Lansbury PT Jr. Seeding “one-dimensional crystallization" of amyloid: a pathogenic mechanism in Alzheimer's disease and scrapie? Cell 1993;73(6):1055-8.

[39] Jarrett JT, Berger EP, Lansbury PT Jr. The carboxy terminus of the beta amyloid protein is critical for the seeding of amyloid formation: implications for the pathogenesis of Alzheimer's disease. Biochemistry 1993;32(18):4693-7.

[40] Scheuner D, Eckman C, Jensen M, et al. Secreted amyloid beta-protein similar to that in the senile plaques of Alzheimer's disease is increased in vivo by the presenilin 1 and 2 and APP mutations linked to familial Alzheimer's disease. Nat Med 1996;2(8):864-70.

[41] Xia W, Zhang J, Perez R, Koo EH, Selkoe DJ. Interaction between amyloid precursor protein and presenilins in mammalian cells: implications for the pathogenesis of Alzheimer disease. Proc Natl Acad Sci U S A 1997;94(15):8208-13.

[42] De Strooper B. Aph-1, Pen-2, and Nicastrin with Presenilin generate an active gammaSecretase complex. Neuron Apr 10 2003;38(1):9-12.

[43] Martoglio B, Golde TE. Intramembrane-cleaving aspartic proteases and disease: presenilins, signal peptide peptidase and their homologs. Hum Mol Genet Oct 15 2003;12 Spec No 2: R201-6.

[44] Wolfe MS, Xia W, Ostaszewski BL, Diehl TS, Kimberly WT, Selkoe DJ. Two transmembrane aspartates in presenilin-1 required for presenilin endoproteolysis and gamma-secretase activity [see comments]. Nature 1999;398(6727):513-7. 
[45] McGowan E, Pickford F, Kim J, et al. Abeta42 is essential for parenchymal and vascular amyloid deposition in mice. Neuron Jul 21 2005;47(2):191-9.

[46] Funato H, Yoshimura M, Kusui K, et al. Quantitation of amyloid beta-protein (A beta) in the cortex during aging and in Alzheimer's disease. Am J Pathol Jun 1998;152(6):1633-40.

[47] Morishima-Kawashima M, Oshima N, Ogata H, et al. Effect of apolipoprotein E allele epsilon 4 on the initial phase of amyloid beta-protein accumulation in the human brain. Am J Pathol Dec 2000;157(6):2093-9.

[48] Scheuner D, Eckman C, Jensen M, et al. Secreted amyloid beta-protein similar to that in the senile plaques of Alzheimer's disease is increased in vivo by the presenilin 1 and 2 and APP mutations linked to familial Alzheimer's disease [see comments]. Nat Med 1996;2(8): $864-70$.

[49] Borchelt DR, Thinakaran G, Eckman CB, et al. Familial Alzheimer's disease-linked presenilin 1 variants elevate Abeta1-42/1-40 ratio in vitro and in vivo. Neuron 1996;17(5): $1005-13$.

[50] Citron M, Westaway D, Xia W, et al. Mutant presenilins of Alzheimer's disease increase production of 42-residue amyloid beta-protein in both transfected cells and transgenic mice. Nat Med Jan 1997;3(1):67-72.

[51] Blessed G, Tomlinson BE, Roth M. The association between quantitative measures of dementia and of senile change in the cerebral grey matter of elderly subjects. Br J Psychiatry Jul 1968;114(512):797-811.

[52] McKee AC, Kosik KS, Kowall NW. Neuritic pathology and dementia in Alzheimer's disease. Ann Neurol 1991;30(2):156-65.

[53] Nagy Z, Esiri MM, Jobst KA, et al. The effects of additional pathology on the cognitive deficit in Alzheimer disease. J Neuropathol Exp Neurol Feb 1997;56(2):165-70.

[54] Cummings BJ, Pike CJ, Shankle R, Cotman CW. Beta-amyloid deposition and other measures of neuropathology predict cognitive status in Alzheimer's disease [see comments]. Neurobiol Aging 1996;17(6):921-33.

[55] Davis DG, Schmitt FA, Wekstein DR, Markesbery WR. Alzheimer neuropathologic alterations in aged cognitively normal subjects. J Neuropathol Exp Neurol Apr 1999;58(4): $376-88$.

[56] Yankner BA, Duffy LK, Kirschner DA. Neurotrophic and neurotoxic effects of amyloid beta protein: reversal by tachykinin neuropeptides. Science 1990;250(4978):279-82.

[57] Pike CJ, Burdick D, Walencewicz AJ, Glabe CG, Cotman CW. Neurodegeneration induced by beta-amyloid peptides in vitro: the role of peptide assembly state. J Neurosci Apr 1993; 13(4):1676-87.

[58] Pike CJ, Walencewicz AJ, Glabe CG, Cotman CW. In vitro aging of beta-amyloid protein causes peptide aggregation and neurotoxicity. Brain Res 1991;563(1-2):311-4.

[59] Geula C, Wu CK, Saroff D, Lorenzo A, Yuan M, Yankner BA. Aging renders the brain vulnerable to amyloid beta-protein neurotoxicity [see comments]. Nat Med 1998;4(7):827-31.

[60] Frautschy SA, Baird A, Cole GM. Effects of injected Alzheimer beta-amyloid cores in rat brain. Proc Natl Acad Sci U S A Oct 1 1991;88(19):8362-6.

[61] Kowall NW, Beal MF, Busciglio J, Duffy LK, Yankner BA. An in vivo model for the neurodegenerative effects of beta amyloid and protection by substance P. Proc Natl Acad Sci U S A Aug 15 1991;88(16):7247-51.

[62] Walsh DM, Lomakin A, Benedek GB, Condron MM, Teplow DB. Amyloid beta-protein fibrillogenesis. Detection of a protofibrillar intermediate. J Biol Chem 1997;272(35): 22364-72.

[63] Klein WL, Stine WB Jr, Teplow DB. Small assemblies of unmodified amyloid beta-protein are the proximate neurotoxin in Alzheimer's disease. Neurobiol Aging May-Jun 2004;25(5): $569-80$.

[64] Lambert MP, Barlow AK, Chromy BA, et al. Diffusible, nonfibrillar ligands derived from Abeta1-42 are potent central nervous system neurotoxins. Proc Natl Acad Sci U S A 1998;95(11):6448-53. 
[65] Walsh DM, Klyubin I, Fadeeva JV, Rowan MJ, Selkoe DJ. Amyloid-beta oligomers: their production, toxicity and therapeutic inhibition. Biochem Soc Trans Aug 2002;30(4):552-7.

[66] Gong Y, Chang L, Viola KL, et al. Alzheimer's disease-affected brain: presence of oligomeric A beta ligands (ADDLs) suggests a molecular basis for reversible memory loss. Proc Natl Acad Sci U S A Sep 2 2003;100(18):10417-22.

[67] Walsh DM, Klyubin I, Fadeeva JV, et al. Naturally secreted oligomers of amyloid beta protein potently inhibit hippocampal long-term potentiation in vivo. Nature Apr 4 2002; 416(6880):535-9.

[68] Wang HW, Pasternak JF, Kuo H, et al. Soluble oligomers of beta amyloid (1-42) inhibit long-term potentiation but not long-term depression in rat dentate gyrus. Brain Res Jan 11 2002;924(2):133-40.

[69] Lue LF, Kuo YM, Roher AE, et al. Soluble amyloid beta peptide concentration as a predictor of synaptic change in Alzheimer's disease. Am J Pathol Sep 1999;155(3):853-62.

[70] McLean CA, Cherny RA, Fraser FW, et al. Soluble pool of Abeta amyloid as a determinant of severity of neurodegeneration in Alzheimer's disease. Ann Neurol Dec 1999;46(6):860-6.

[71] Jacobsen JS, Wu CC, Redwine JM, et al. Early-onset behavioral and synaptic deficits in a mouse model of Alzheimer's disease. Proc Natl Acad Sci U S A Mar 28 2006;103(13): 5161-6.

[72] Lesne S, Koh MT, Kotilinek L, et al. A specific amyloid-beta protein assembly in the brain impairs memory. Nature Mar 16 2006;440(7082):352-7.

[73] Hsia AY, Masliah E, McConlogue L, et al. Plaque-independent disruption of neural circuits in Alzheimer's disease mouse models. Proc Natl Acad Sci U S A Mar 16 1999;96(6):3228-33.

[74] Comery TA, Martone RL, Aschmies S, et al. Acute gamma-secretase inhibition improves contextual fear conditioning in the $\mathrm{Tg} 2576$ mouse model of Alzheimer's disease. J Neurosci Sep 28 2005;25(39):8898-902.

[75] Dodart JC, Bales KR, Gannon KS, et al. Immunization reverses memory deficits without reducing brain Abeta burden in Alzheimer's disease model. Nat Neurosci May 2002;5(5): $452-7$.

[76] Kotilinek LA, Bacskai B, Westerman M, et al. Reversible memory loss in a mouse transgenic model of Alzheimer's disease. J Neurosci Aug 1 2002;22(15):6331-5.

[77] Lee EB, Leng LZ, Zhang B, et al. Targeting amyloid-beta peptide (Abeta) oligomers by passive immunization with a conformation-selective monoclonal antibody improves learning and memory in Abeta precursor protein (APP) transgenic mice. J Biol Chem Feb 17 2006; 281(7):4292-9.

[78] McLaurin J, Kierstead ME, Brown ME, et al. Cyclohexanehexol inhibitors of Abeta aggregation prevent and reverse Alzheimer phenotype in a mouse model. Nat Med Jul 2006;12(7): $801-8$.

[79] Townsend M, Cleary JP, Mehta T, et al. Orally available compound prevents deficits in memory caused by the Alzheimer amyloid-beta oligomers. Ann Neurol Dec 2006;60(6): $668-76$. 